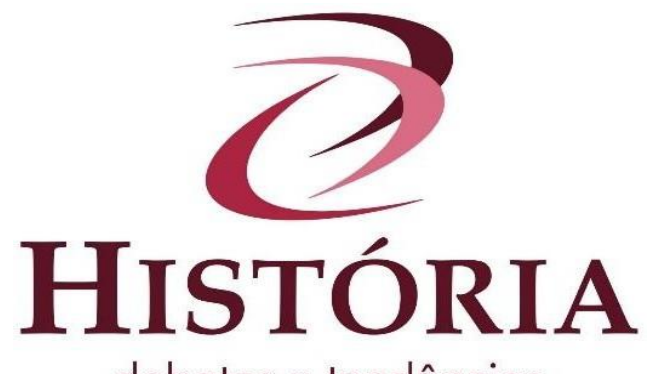

\title{
La Agroindustria Yerbatera Argentina: Agro, conflictos y políticas públicas en los márgenes. Misiones (1953- 2013)
}

\section{Agroindustria Ervatera Argentina: Agro, conflitos e políticas públicas nas margens. Misiones (1953- 2013)}

\section{Argentine Yerba Mate Agroindustry: Agriculture, conflicts, and public politics in frontier provinces, Misiones $(1953$ - 2013)}

\author{
Lisandro Rodríguez*
}

\begin{abstract}
Resumen
El objetivo de este artículo es estudiar la construcción social e histórica de la Región Yerbatera Argentina. El eje de análisis se detiene en examinar las transformaciones del modelo económico y sus repercusiones en esta agroindustria. La propuesta consiste en describir las estrategias y metodologías desplegadas por el Estado para la promoción del desarrollo rural. Al mismo tiempo, se pretende reconocer las relaciones de poder y los conflictos agrarios que se suscitan en un territorio marginal y de frontera como lo es la actual provincia de Misiones. La premisa es identificar los desequilibrios agrarios al interior de esta región como consecuencia de la concentración e integración en la actividad. Boletines oficiales de la Comisión Reguladora de la Yerba Mate (CRYM); datos del Instituto Nacional de la Yerba Mate (INYM), documentos originales de las cooperativas yerbateras (memorias y balances), publicaciones periódicas del Movimiento Agrario de Misiones y entrevistas a actores claves conforman el corpus documental de este abordaje.

Palabras clave: Agroindustria. Estado. Región. Yerba Mate.
\end{abstract}

\section{Resumo}

O objetivo deste artigo é estudar a construção social e histórica da região ervatera argentina. O eixo de análise para no exame das transformações do modelo econômico e suas repercussões nesta agro- indústria. A proposta consiste em descrever as estratégias e metodologias implantadas pelo Estado para a promoção do desenvolvimento rural. Ao mesmo tempo, pretende-se reconhecer as relações de poder e os conflitos agrários que surgem em um território marginal e fronteiriço, como a atual província de Misiones. A premissa é identificar os desequilíbrios agrários nessa região como resultado da concentração e integração na atividade. Boletins oficiais da Comissão Reguladora da Yerba Mate (CRYM); dados do Instituto Nacional de Ervas Mate (INYM), documentos originais das cooperativas yerbateras (memórias e balanços), publicações periódicas do Movimento Missionário Agrário e entrevistas com atores-chave compõem o corpus documental dessa abordagem.

Palavras-chave: Agroindústria. Estado. Região. Erva Mate.

\section{Abstract}

The object of this article is to study the social and historical construction of the region that produces Yerba Mate (from Spanish) in Argentina. The main point of this analysis is centered on examining the transformation of the economic model and its repercussions on this agroindustry. 
The approach consists of the description of strategies and methodologies presented by the State for the promotion of rural development. At the same time, we aim to recognize the relationship between power and the agrarian conflicts that arise in a territory that is marginal and on the frontier such as the present province of Misiones. The premise is to identify the agrarian imbalances in the interior of this region as a consequence of the concentration and integration in the activity. Official Bulletins of the Regulating Commission for the Yerba Mate (CRYM) (initials in Spanish); data from the National Institute of Yerba Mate (INYM) (initials in Spanish), original documents from the Yerba Mate Cooperatives, (financial reports and balances), periodic publications from the Agrarian Movement in Misiones (MAM) (initials in Spanish) and interviews with key personalities make up the documentary corpus of this approach.

Keywords: Agroindustry. State. Region. Yerba Mate.

\section{Introducción}

La yerba mate (Ilex Paraguariensis) es una planta originaria de América del Sur y está presente en Brasil (Estados de Paraná, Matto Grosso y Santa Catalina), Paraguay y Argentina. En este último país, el cultivo se localiza en el Nordeste, más específicamente en las provincias de Misiones (que aporta el 90\% de la producción de yerba mate y de la superficie sembrada con dicho cultivo a nivel nacional) y Corrientes, constituyéndose en una producción netamente regional y orientada principalmente al mercado interno. La actividad, de gran importancia social y económica, además de presentar un alto índice de consumo -6 kgs per cápita- moviliza tanto a productores como al sector industrial y comercial. El $87 \%$ de la producción está dirigida al mercado argentino y el 13\% restante se exporta generando 18,2 millones de U\$S/anuales. Para 2013 la actividad agroindustrial yerbatera representa para el valor bruto de la producción (VBP) 5800 millones de pesos (hasta la etapa de molienda) y, si se considera al agregado de la comercialización minorista, resulta en un valor de 7800 millones de pesos anuales. ${ }^{i}$

El accionar del Estado es indispensable para entender la construcción social e histórica del territorio definido como Región Yerbatera Argentina y comprender los alcances de las políticas públicas destinadas a la promoción del desarrollo rural. Desde principios del siglo XIX, el ejecutivo nacional promueve la colonización yerbatera en el Territorio Nacional de Misiones (principalmente con inmigrantes europeos), determina los mecanismos para el asentamiento poblacional y acceso a la tierra, al tiempo que genera las condiciones para el establecimiento y desarrollo agroindustrial en base a la plantación del Ilex. Además, este cultivo es un componente fundamental para el surgimiento y consolidación de la explotación agrícola familiar.

El marco temporal propuesto para este trabajo parte desde la provincialización de Misiones $^{\text {ii }}$ en 1953 y finaliza en 2013 cuando la yerba mate es declarada por el Congreso de la Nación como "Infusión Nacional” por intermedio de la Ley 26871. En este periodo se producen cambios estructurales en el régimen social de acumulación que afectan de manera directa la estructura agraria misionera en general y a la yerbatera en particular. El desarrollo de la agroindustria tabacalera, el avance de la foresto- industria, la integración y concentración son las características más notoria en la región. Las consecuencias para el sector yerbatero están 
determinadas por los desequilibrios y la polarización cada vez más marcada entre los grandes plantadores y los pequeños y medianos productores.

Determinar las rupturas y reconocer las continuidades durante este proceso histórico forman parte sustancial de la propuesta de estudio en esta comunicación. Observar a escala regional los cambios del modelo económico y las especificidades del régimen social de acumulación implica que se ponderen a distintos actores. El Estado (nacional y provincial) y sus propuestas de desarrollo rural devienen en agente insoslayable para el análisis. En este sentido, las políticas públicas permiten una visión del Estado en acción, en un proceso social en el que se vincula con otras fuerzas sociales y que se define por un conjunto de acciones u omisiones, que manifiestan una determinada modalidad de intervención en relación con una cuestión que concita la atención, interés o movilización de otros sectores de la sociedad civil (Ozslak y O`Donell, 1995).

Los modos de actuar por parte del Estado pueden ser analizados a través de la noción de capacidad estatal, entendida como las posibilidades de acción que tiene esta institución a través de diferentes políticas públicas, programas, marcos institucionales y demás instrumentos (Lattuada; Márquez y Neme, 2012). A su vez, debe ser una estructura institucional perdurable y eficaz y no un aparato de medición respecto de la pericia y de la perspicacia de los tecnócratas que lo integran (Evans, 1996). En este sentido, no sólo hay que dar cuenta de los marcos administrativos y las reglas del juego, sino también de las organizaciones y sus posicionamientos, como así también de sus acciones en determinados contextos (Repetto, 2004).

En la agroindustria yerbatera, las políticas estatales tienen un doble marco de análisis para el periodo y el área en estudio. Aquellas que responden directamente al decisiones del Estado Nacional y las que se ejecutan desde el Ejecutivo de Misiones. Además, la zona productora comprende al norte de Corrientes, hecho que explica la injerencia nacional, más allá de las decisiones que puedan tomar internamente cada una de las provincias partícipes. En no pocos casos, las medidas determinan pujas de poderes, que se traducen en conflictos y lucha de intereses.

En Misiones la acción del Estado en el agro está representada por dos instituciones principales: el INTA, dedicado a la investigación y a la extensión y el actual Ministerio del Agro y la Producción -Ministerio de Asuntos Agrarios (MAA) hasta 1999- como ente de aplicación de políticas y desarrollo agropecuario. La labor del Ministerio está estructurada en torno a productos como la yerba mate, tabaco y té, además de cultivos no tradicionales como el citrus y la ganadería. En 1999 se crea la Dirección de Pequeños Agricultores, Huertas y Ferias Francas. El desempeño de estas agencias, enmarcado en la estrategia clásica de modernización estatal, viene experimentando modificaciones desde mediados de la década de 1980 (Schiavoni y De Micco, 2008).

Con respecto a la producción, cosecha, elaboración y comercialización de la yerba mate, la entidad oficial por excelencia esta representada por la Comisión Reguladora de la Yerba Mate 
(CRYM). Su creación por parte del Estado Nacional data de 1935 y su accionar se extiende hasta 1991, cuando los decretos de desregulación de juntas y comisiones reguladoras ponen fin a 56 años de injerencia estatal. La entidad cuenta hasta 1987 con un Mercado Concentrador que se encarga de recibir las consignaciones de yerba mate para su comercialización. Luego de una década de libre mercado (1991- 2001), el sector yerbatero experimenta la presencia de una nueva entidad: el Instituto Nacional de la Yerba Mate (INYM) que se crea como ente oficial en 2002. A diferencia de su predecesora, la nueva institución no se gesta como una entidad estatal, no cuenta con un mercado concentrador y en la práctica dista mucho del accionar de la CRYM.

Las acciones colectivas y las prácticas asociativas de los productores representan también una herramienta de análisis clave. Propician la articulación con los mercados de productos e insumos agropecuarios y de crédito, con el propósito último de mejorar el nivel de vida de las familias rurales y aumentar su peso en la economía agropecuaria y en la dinámica social (Lattuada, 2006). Además, constituyen espacios donde se dirimen estrategias y posicionamientos frente al accionar estatal. Entonces, el estudio de las instituciones cooperativas (en su aspecto económico) resulta fundamental para dar cuenta del nexo entre los productores yerbateros y los procesos de valorización del producto. Se consideran en este sentido, a las cooperativas de yerba mate, en particular a las que agrupan a agricultores familiares. Se propone como estudio de caso a la Cooperativa Minifundista Río Paraná, ubicada en la localidad de Oberá (zona centro de la provincia). Al mismo tiempo se ponderan a las asociaciones de productores (aspecto reivindicativo) como el caso del Movimiento Agrario de Misiones (MAM).

\section{Estado y agro en la región yerbatera. Misiones (1953- 1976)}

En 1953 Misiones deja de ser Territorio Nacional para adquirir el rótulo de provincia argentina. A pesar de obtener la "ciudadanía plena" en términos políticos, el status adquirido no resulta suficiente para solucionar las contradicciones entre intereses económicos locales y extra regionales que identifican a la agroindustria yerbatera. Entonces, el marco temporal propuesto permite identificar los alcances y los límites del accionar del Estado provincial en áreas que hasta entonces eran de competencia nacional, al tiempo que admite analizar las relaciones y tensiones económicas, políticas y sociales que se establecen entre ambas esferas (Nación- provincia) y demás miembros de la sociedad civil.

Cuando se produce la provincialización, la actividad yerbatera está marcada por la liberación de nuevos cultivos ${ }^{\mathrm{iii}}$ (1952-1966) que, entre otros factores, da origen a la denominada y discutida- superproducción (debido a la existencia de stock en los galpones de la CRYM) agudizada además por la importación del producto desde el Paraguay. El contexto deviene delicado en la cuenca productiva y la crisis agraria se prolonga con periodos de sobreproducción y bajos precios (Bartolomé, 1975; Schiavoni, 1995; Slutzky, 2011). Además, resulta fundamental tener en cuenta la constante interrupción democrática ejercida por gobiernos dictatoriales.

Un punto de inflexión en término económicos y políticos lo constituye la decisión 
gubernamental de prohibir totalmente la cosecha en 1966, luego de haber alentado unos pocos años antes la libre plantación del ilex. La medida ilustra la falta de proyección oficial a mediano y largo plazo en políticas públicas dirigidas al agro en las regiones marginales y específicamente a la zona yerbatera. Estos avatares conducen a una polarización entre los pequeños y medianos productores y el segmento de los grandes plantadores, al tiempo que provoca un descontento de los primeros respecto de las medidas del Estado (tanto nacional como provincial), que en no pocas oportunidades favorecen a los de mayor poder de producción. Ejemplo de esta situación es que algunos plantadores pueden -mediante un amparo judicial- realizar la cosecha en 1966, año de la prohibición total. El hecho genera un malestar de gran parte de los colonos yerbateros y sienta un precedente de "parcialidad" en las decisiones gubernamentales para la agroindustria yerbatera. Las percepciones que tienen los sujetos sociales respecto de las políticas públicas difieren y sucintan conflictos, convirtiendo a las oficinas de la CRYM en un escenario donde se dirimen las correlaciones de fuerza y se establecen las relaciones de poder.

Cuando se produce la prohibición no sólo se muestra una decisión del gobierno, sino que también se puede observar las estrategias de los grandes productores para evadir la prohibición. Presentaron amparos que tomaron curso. En cambio, el pequeño y mediano colono de nuevo sufrió las consecuencias. Eran hechos que nos hacían pensar que la mejor opción era juntarnos los productores que teníamos los mismos intereses para de esa manera entablar una lucha sólida (Entrevista a Juan Berent, fundador del MAM, Alberdi, Misiones, 2019).

El proceso de diferenciación agraria se consolida en la región y da origen a la concentración e integración de la actividad (mercado oligopsónico) que en la actualidad persiste y se agudiza (Rau, 2012). La ya mencionada CRYM y el Mercado Concentrador son las entidades donde se materializan estas disputas y hacia quiénes se dirigen las demandas, principalmente por parte de los pequeños productores asociados en cooperativas o vinculados a entidades gremiales creadas en la primera mitad del siglo XX, como la Asociación Rural Yerbatera Argentina (ARYA), el Centro Agrario Yerbatero Argentino (CAYA), o la Federación de Cooperativas Agrícolas de Misiones (Fedecoop). Desde 1953 y hasta fines de la década de 1970 la discusión tuvo a la limitación de la cosecha como punto más destacado. Entonces, las políticas estatales apuntan a regular la producción ante la presión -cada vez más resonante- de estas entidades que agrupan a los productores de yerba mate.

Las versiones sobre la limitación son disímiles. Desde la entidad oficial se destaca la importancia de la misma en la consecución de un mercado yerbatero armonioso y estable

Al cumplirse el quinto año de cosechas limitadas se ha tenido la satisfacción de acordar un sensible aumento de la producción nacional del año en curso. Esta medida corrobora la eficacia de la regulación impuesta a la yerba mate, por cuanto, no sólo se ha conseguido eliminar los stocks de arrastre, sino que también, se ha logrado ir beneficiando a los plantadores nacionales, con los aumentos paulatinos del consumo, tal como fue previsto al elaborar el plan en procura del equilibrio. ${ }^{\text {iv }}$

Por el contrario, desde las organizaciones reivindicativas y asociativas la postura es opuesta a la que sostiene la entidad estatal y de injerencia nacional. 
Todo el fondo de la cuestión reside en un problema innecesariamente creado: la superproducción vinculado a su vez a la solución propuesta: la limitación. Allí nació todo y de allí surgen las derivaciones de estos momentos, por gravitación de los hechos o por la intencionada explotación de las circunstancias. ${ }^{\mathrm{V}}$

Los argumentos encontrados describen un complejo contexto para la economía yerbatera. Las voces de los protagonistas (Estado y productores) representan una imagen de los acontecimientos, donde el reclamo gremial permite inferir las críticas hacia las políticas estatales, que no siempre se ajustan a las necesidades de los productores, al tiempo que ilustra la puja de poderes y el conflicto de intereses entre las partes que conforman esta agroindustria. Si ante la limitación el panorama es caótico, la prohibición agudiza esta situación, al extremo de que los productores realizan entre 1966 y 1967 cosechas clandestinas o disponen del producto consignado en chacra con la idea de reponerlo luego. La crisis yerbatera persiste y se agudiza tanto por el vuelco al mercado libre que ofrece precios más bajos, como por los problemas de orden financiero y económico que dificultan el progreso de los yerbateros (Bolsi, 1986). El comercio exterior aparece como una opción, aunque, como lo evidencian los registros, los niveles exportados son mínimos y no alcanzan a cubrir las condiciones decadentes y, paradójicamente no superan a las importaciones. ${ }^{\mathrm{vi}}$

(...) hemos apoyado también las gestiones realizadas ante el Superior Gobierno de la Nación para lograr el decreto de "no cosecha", acatándola luego plenamente. Nos place destacar que el $99 \%$ de nuestros asociados ha compartido nuestro criterio en este sentido. Lamentablemente algunas empresas y grupos de productores han obtenido fallo favorable en un recurso de amparo interpuesto ante el Poder Judicial contra este decreto de no cosecha, lo que constituye un antecedente altamente inquietante para quienes, como nosotros, confían en la eficacia de una regulación oficial de la economía yerbatera por intermedio de los organismos existentes. ${ }^{\text {vii }}$

Como si el contexto socio- económico no fuese caótico, en 1971 la CRYM adeuda a los productores el pago de la prenda yerbatera correspondientes a seis periodos anuales. La persistencia de la crisis es agobiante. El cooperativismo yerbatero expone esta situación y reafirma su carácter reivindicativo al denunciar la falta de solución por parte de su principal interlocutor: el Estado.

Los problemas que afectan a la economía de este producto no encontraron solución. Las presentaciones, delegaciones, entrevistas, publicaciones y el permanente clamor de los productores continúan siendo "campanas de palos", para los oídos de quienes dependen las soluciones (...). Creemos que solamente un productor yerbatero puede admitir que, en 1971 se adeuden todavía saldos que corresponden a la consignación de la cosecha de 1965 . Solamente a él le toca observar impotente, como sus acreencias se esfuman devoradas por una feroz inflación por la insolvencia de un organismo que se supone creado para la defensa de sus legítimos intereses y al que la inercia oficial mantiene maniatado (...). Solamente un yerbatero admitirá como posible que mientras él se ve constreñido a dejar un $70 \%$ de su propia producción en la planta se posibilite generosamente, por las autoridades nacionales, la introducción del producto similar extranjero. ${ }^{\text {viii }}$

La situación conlleva a un descontento generalizado de los productores, ya no únicamente de los yerbateros, porque el impacto de la crisis se siente también en el té y en el tabaco, es decir prácticamente en todo el agro misionero. En este escenario hace su aparición el Movimiento 
Agrario Misionero (MAM) que se constituye en la localidad de Oberá en mayo de 1971. Las principales reivindicaciones se orientan en mejorar los precios de los productos agrícolas y sus instrumentos de comercialización. Desde el momento de su fundación se consolida como la organización gremial de mayor relevancia y legitimidad debido a su capacidad de movilización en toda la provincia (Bartolomé, 1982). El movimiento surge en representación del conjunto de agricultores cuyos intereses no se diversifican en otras ramas de la producción. No obstante, adscriben al mismo e impulsan su fundación dirigentes de cooperativas, entre las que se encuentran algunas de gran poder económico y que, con el transcurso del tiempo provocan las fracciones y divisiones en el seno del movimiento, resaltando así las diferencias de clase entre los sujetos que conforman la economía yerbatera.

El carácter que asume el MAM es más gremial y reivindicativo que económico. A través de Amanecer Agrario, su órgano de difusión oficial, es posible observar este accionar. Como las demás asociaciones agrarias, el Estado (provincial y nacional) es el principal destinatario de las reivindicaciones y demandas. A diferencia de las demás entidades a las críticas se suman las movilizaciones y protestas, otorgando al movimiento un grado de lucha organizada inexistente hasta entonces. Así, ante el contexto descripto de falta de pago de la prenda yerbatera por parte de la CRYM y ante la ausencia de soluciones por parte del Estado, las calles fueron los espacios de reclamo de los productores organizados por el MAM

El paro del MAM lo logró: Por fin se paga la yerba del 65. Fueron dos días largos, 48 horas vividas minuto a minuto. Todos los colonos de Misiones, y muchos que no son colonos sabían que se jugaban una "carta brava". Si el gobierno no escuchaba nuestros reclamos, si no atendía a nuestros petitorios, no podría ignorar el eco que llega de una provincia paralizada, una provincia que por dos días gritó con el silencio de las fábricas, con los comercios clausurados, con las chacras inmóviles, que Misiones está harta de injusticias. ${ }^{\text {ix }}$

La CRYM en tanto institución estatal encargada de regular la actividad yerbatera también es objeto de las críticas y demandas del MAM. A los duros cuestionamientos de las cooperativas yerbateras representadas por la Fedecoop, se suman el posicionamiento del movimiento que considera que la entidad oficial es un mero instrumento de los grandes plantadores e industriales

La CRYM en lugar de ser un organismo que regula la producción de yerba, es un organismo al servicio de los grandes industriales, de los grandes productores, que la utilizan para ocultar sus maniobras, ya sea la compra de la yerba negra, el manejo del dinero de los productores, el contrabando de yerba, el manejo del precio de la yerba seca etc. ${ }^{\mathrm{x}}$

La década de 1960-1970 se caracteriza por un permanente estado de crisis agrícola en la región yerbatera argentina. Se produce además, el fin de la expansión de la frontera agraria y de la colonización; hecho que acentúa el agotamiento y la concentración de la tierra. La última variable no es un dato menor en la configuración social actual del sujeto yerbatero. El cambio del modelo económico y el régimen de acumulación neoliberal (que se consolida en los 90) modifica la estructura agraria (tanto en la tenencia de tierra, como así también en las formas de producir y 
comercializar) y las estructuras internas de las organizaciones (gremiales y económicas) de los productores.

El contexto posibilita además, la incorporación del tabaco y la foresto- industria, factores que modifican el paisaje agrario, como así también las decisiones estatales orientadas al sector rural. Para fines del decenio, el productor percibe valores sustanciales menores a los recibidos al inicio del periodo. El descenso de los precios es muy notorio para el caso del té y del tung, y menor para la yerba y el tabaco, cultivos donde es importante la intervención del Estado en la primera etapa de la comercialización, a través de la CRYM y el Fondo Especial del Tabaco (FET). En este contexto, el costo de vida aumenta en forma constante y la reproducción social del pequeño y mediano productor se mantiene a costa de un desmejoramiento de sus condiciones de vida (Schiavoni, 1995).

\section{Cambio en la estructura agraria en Misiones (1980- 2013)}

La realidad del agro en Misiones no es la excepción de lo que acontece en el resto de América Latina. En consonancia con el contexto nacional e internacional, el rol de las instituciones conducentes al desarrollo rural evidencia un proceso de transformación desde mediados de la década de 1980 y acentuado en el decenio posterior. A partir de entonces, el vínculo que establece el Estado (a través de sus entes oficiales) con las empresas y organizaciones agrarias tiene como objetivos principales la competitividad y la eficiencia. Los enunciados no responden a una premisa aislada, sino que dan cuenta de un modelo de acumulación económica del capitalismo agarario y denotan la consolidación del agronegocio por sobre la agricultura.

En este escenario de transformaciones, en la provincia de Misiones el complejo agroindustrial tabacalero se convierte en la principal agencia de difusión tecnológica entre los pequeños productores, modificando el paisaje agrario y reorientando las prioridades productivas, incluso por sobre la agroindustria yerbatera. Como contrapartida, el estilo tecnológico alternativo se orienta a la agricultura orgánica, a los sistemas agrarios, a la recuperación de semillas y selección de variedades nativas (Schiavoni y De Micco, 2008).

Los cambios en el orden económico y la necesidad de re- definir prioridades para el agro afectan a la metodología hasta entonces desplegadas por el Estado, como así también a las estrategias de producción y comercialización de los productores y sus organizaciones de acción colectiva. La intensificación del capital para lograr una producción competitiva y la incorporación de nuevas tecnologías conduce a la modificación de la estructura agraria provincial, con la consolidación y expansión de la actividad forestal. El proceso se 
inicia a partir de 1960 y para 2002 ya supera a la suma del resto de los cultivos implantados. Misiones es la provincia que más inversiones recibe entre 1992 y 2000. El 50 $\%$ de las inversiones provienen del Estado y más del $40 \%$ de empresas privadas extranjeras, mayoritariamente de capitales chilenos. La mayor parte se orienta a la implantación, adquisición de plantaciones forestales y de grandes empresas (como la compra de Celulosa Puerto Piray y de Alto Paraná por parte de la forestal chilena Arauco).xi El resultado de esa política genera una superficie forestada que casi se duplica entre 1992 y 2004, pasando de las 260.700 ha a 420.700, alcanzando un ritmo de crecimiento de 17.000 ha por año (Arzeno y Ponce, 2012).

En la modificación de la estructura agraria y en la implementación de las tecnologías e innovaciones productivas, la yerba mate no ocupa el lugar central, dado que la preponderancia del complejo tabacalero y la forestación representan una tendencia creciente, particularmente en el norte provincial. Sin embargo, la actividad yerbatera aún tiene un sitio destacado para la mayoría de los productores y agricultores familiares, tanto en el orden económico como en el simbólico. Los guarismos así lo indican, porque a pesar de las recurrentes crisis del sector, la difusión de este cultivo perenne y de necesaria transformación industrial, sigue siendo muy importante. En la región yerbatera existen alrededor de 17.444 explotaciones aunque los márgenes de participación del sector de productores familiares y el marco institucional previsto para la negociación sobre las condiciones de producción y distribución de los ingresos de la yerba mate se ven modificados (Slutzky, 2011).

El $76 \%$ de los productores tienen menos de 10 hectáreas cultivadas, ocupando el $52 \%$ de la superficie. En tanto el $24 \%$ restante tiene más de 10 hectáreas y poseen el $48 \%$ del área. A principios de la década de 1980 se crea un Comité de Investigaciones denominado CONINMATE, que establece acuerdos con el Instituto Nacional de Tecnología Agropecuaria (INTA) para las mejoras en el sector. En este contexto se aprueban nuevas plantaciones (20.000 hectáreas) en el Nordeste de la provincia, acción que se enmarca en un nuevo plan de colonización y en la expansión de la frontera agraria. A fines de la década, la situación yerbatera es crítica, las nuevas plantas generan superproducción y las innovaciones parecen no representar una solución en el corto plazo. El accionar estatal enfrenta nuevamente limitaciones ya conocidas en el pasado y sus propuestas de desarrollo rural se ven condicionadas por el contexto socio- económico, que se manifiesta con una nueva crisis y provoca nuevos enfrentamientos con los productores.

En términos institucionales en 1987 desaparece -después de 50 años de existencia- 
el Mercado Concentrador. Es un indicio del retiro estatal que se acentúa años más tarde con la disolución de la cuestionada CRYM y la desregulación estatal por intermedio del decreto 2284/91. A partir de entonces el mercado yerbatero queda sujeto a las decisiones de los molineros y cadenas de supermercados hasta 2002 cuando se crea el Instituto Nacional de la Yerba Mate (INYM), cuyo accionar es más criticada que su antecesora CRYM.

Uno de los aspectos fundamentales de la actividad yerbatera es la producción. El perfil tecnológico orientado a este eslabón se asocia con la densidad y las técnicas de cultivo, donde el rendimiento por hectárea está determinado por: a) la edad de las plantaciones, b) la densidad de plantas por superficie, c) los componentes tecnológicos; d) la utilización de agroquímicos (plaguicidas, herbicidas, abonos y fertilizantes), e) el manejo de poda y cosecha (el manejo inadecuado de podas y cosechas condicionan el rendimiento productivo de la yerba mate, esto asociado al clima, altura y edad de las plantas entre otras variables).

Con respecto a la densidad por hectárea, la propuesta estatal a través de las instituciones involucradas (especialmente el INTA y el INYM) es optimizar los plantines para alcanzar mejores rendimientos a futuro, como así también el reemplazo de plantaciones antiguas. Estas medidas se relacionan a las modificaciones enunciadas, dado que la expansión del complejo tabacalero y particularmente la foresto- industria demandan disponibilidad de tierras, factor crítico en Misiones como consecuencia del fin de la expansión agraria. En la práctica, el principal inconveniente que se registra es la capacidad real que tienen los productores para incorporar estas nuevas plantas. El estrato mayoritario de yerbateros está compuesto por pequeños y medianos productores, cuya capacidad económica condiciona -históricamente- la posibilidad de anexar el uso de las nuevas tecnologías. El Plan Estratégico para el Sector Yerbatero (2013- 2028) elaborado por el ente oficial advierte esta situación

En cuanto a la aplicación de tecnología las empresas líderes en el sector están realizando plantaciones de alta densidad con rendimientos por encima de los $10.000 \mathrm{~kg}$ por hectáreas, están mecanizando o semimecanizando el proceso de cosecha. Se prevé un futuro cercano que en las plantaciones más importante se trabajará con diferentes niveles de mecanización y que el trabajo del tarefero será más especializado. Se ve como un riesgo la pérdida de competitividad y desaparición de los pequeños y medianos productores. También se prevé en el mediano plazo que aumenten las exigencias de calidad total para el producto, haciendo necesaria la aplicación de buenas prácticas agrícolas y la garantía de mejores condiciones laborales. ${ }^{\text {xii }}$

En términos generales existen (y conviven) dos modelos de producción distintos acorde al perfil tecnológico: el tradicional de baja densidad y el intensivo o moderno, que 
se corresponde con la producción de media o alta densidad. Esta diferencia refleja dos tipos de producciones y al mismo tiempo, evidencia distintos categorías de productores. Las plantaciones de perfil bajo se caracterizan por tener una densidad menor a 1200 plantas por hectáreas y un rendimiento menor a $3000 \mathrm{~kg}$. En el otro extremo, el denominado perfil intensivo, posee rendimientos marcadamente superiores (hasta 3,25 más) (Coninagro- Fedecoop, 2014).

El objetivo fundamental por parte del Estado (nacional y provincial) es reducir la brecha tecnológica entre estos dos estratos. En este sentido, se registran avances en la incorporación de las innovaciones entre los pequeños productores, en especial a partir de las propuestas desarrolladas por el Programa Regional de Asistencia al Sector Yerbatero (PRASY) que, con el asesoramiento del INTA ponen a disposición tecnologías para recuperar suelos degradados, manejo de las plantas, cubiertas verdes e incorporación de abonos. Un análisis del alcance de las mismas, determina que los rendimientos alcanzan niveles superiores e incorpora cada vez a más productores (Coninagro- Fedecoop, 2014).

Nosotros recuperamos el yerbal de mi papá a puro esfuerzo y aplicando algunas de las recomendaciones de los ingenieros. Como no podíamos comprar los plantines para reemplazar la yerba vieja, y además hay que tener en cuenta que tarda como cuatro años en entrar en producción, decidimos ir por el lado del mejoramiento de suelo. Incorporamos abonos orgánico y presenciamos algunas charlas sobre cubierta verde. Así de a poco el yerbal mejoró y aumentó su rendimiento por hectárea (Entrevista a Juan, productor yerbatero, Apóstoles Misiones, mayo de 2019).

La entrevista al joven productor apostoleño revela al menos dos situaciones, una asociada al abandono de los yerbales acaecidos desde la libre concurrencia desregulatoria y la segunda el aspecto "positivo" del plan de mejoramiento. En la primera situación (y en el mejor de los casos) son los hijos o familiares directos de los colonos quiénes asumen la responsabilidad de continuar con la producción yerbatera. De no ser así los yerbales quedan abandonados o las chacras son compradas por algún plantador o empresa integrada. En la segunda situación, el mejoramiento representa un progreso si se evalúa de manera individual a la unidad productiva. Es decir, si se tiene en cuenta la variable tiempo en el antes y después de la incorporación de abonos u otros elementos orientados a optimizar las plantaciones. En el esquema grupal, estas unidades (a pesar de su mejora) no pueden competir con aquellas explotaciones que hayan mejorado su perfil tecnológico a partir de nuevas plantas y adopción de otros mecanismos como por ejemplo un sistema de riego por goteo. Los rindes finales de una y otra unidad determinan estas diferenciaciones que, como en todas las situaciones de desigualdad conducen a una asimetría y polarización cada vez mas notoria.

Un elemento central que se desprende de las modificaciones registradas, y que 
constituyen una herramienta fundamental para comprender la realidad de la actividad yerbatera es la concentración e integración. Con respecto a la producción, los dos estratos más grandes, es decir 1115 productores que representa el 7\% del total, aportan más del 50 $\%$ de la materia prima. Si se tiene en cuenta que el precio de referencia de dicha materia es similar para los distintos estratos, se observa que la concentración se agudiza y consolida. Es decir, el precio que a un pequeño productor permite -cuanto mucho- sostenerse en la actividad, generan en los estratos de grandes productores importantes ganancias, reforzando la diferenciación social y productiva, a partir de las posibilidades de inversión en mejoramiento de suelos, fertilización, manejo de plagas, riego, etc. La oportunidad de mayores ganancias en los estratos superiores se intensifica -además- con el proceso de integración vertical que se registra entre grandes plantaciones y la etapa industrial, acción que posibilita aprovechar la economía de escala y la disminución de los costos de intermediación y la carga fiscal (Gortari, 2016).

En síntesis, la implementación de tecnología y la mayor rentabilidad por hectárea de las superficies de los grandes plantadores condicionan a los pequeños y medianos productores a la subsistencia, debido a que no pueden incorporar los mismos niveles tecnológicos y, por ende tampoco pueden competir adecuadamente con los grandes molinos. Los costos de producción se encuentran en función del nivel tecnológico, las densidades y los rendimientos de los cultivos. Los pequeños productores minifundistas sólo logran cubrir los gastos mínimos de mantenimiento, cosecha y flete, llegando incluso a tener márgenes brutos negativos.xiii

Las condiciones descriptas provocan el accionar de los sujetos involucrados, quienes demandan al Estado que interceda en pos del bienestar común del colectivo yerbatero. El punto máximo de conflicto yerbatero se registra en la segunda mitad de la década de 1990 y a principios del nuevo milenio y tiene al precio justo como bandera de lucha (Rau, 2002). La metodología empleada por los productores es conocida en el escenario provincial. Cortes de ruta y movilizaciones son los denominadores comunes del accionar de estos sujetos agrarios. Cuando la libre concurrencia demandan al Estado la intervención a través de una entidad oficial. La creación de INYM en 2002 parecía representar una salida. Empero, el ente se crea como un instituto oficial pero no estatal, cuyos objetivos no son los mismos que la otrora CRYM.

\section{Acción colectiva y persistencia en contextos desfavorables}


A partir de la desregulación yerbatera de 1991 y en el contexto del modelo neoliberal, en la provincia de Misiones se observan cambios en la estructura del Estado con la creación de áreas que atienden específicamente a la agricultura familiar. Al mismo tiempo, se registran reorientaciones de las políticas existentes o creación de otras nuevas, dirigidas a este sector y específicamente orientadas a incrementar la producción de alimentos para los mercados locales. Otro aspecto a tener en cuenta es la diferenciación en relación con el perfil de los beneficiarios que atiende la esfera nacional de intervención con sede en la provincia y aquellas gestadas desde el propio gobierno provincial (Arzeno y Ponce, 2012).

La agricultura familiar es uno de los grupos más afectados por las políticas económicas adoptadas durante el nuevo modelo de acumulación, al tiempo que representan el sector más importante en el interés de la política agropecuaria nacional, por su relevancia en aspectos sociales, territoriales y económicos (IICA, 2011). En este sentido, emergen propuestas de acción colectiva para dar solución a las necesidades de los productores, que por su dotación de recurso y calificación profesional, se encuentran excluidos de la posibilidad de sostenerse económicamente a partir de sus ingresos como productores agropecuarios, o de seguir una trayectoria de reproducción ampliada.

Un primer representante de la agricultura familiar, aunque no el único, son los pequeños productores rurales, entendidos como aquellos que trabajan directamente en sus predios con el apoyo de miembros de su familia o grupo doméstico y cuyos recursos productivos - tierra, capital, ingresos - son relativamente limitados (López Castro y Prividera, 2011). Pero dentro de la categoría de agricultura familiar se acepta que estos pequeños productores puedan tener diferentes niveles de capitalización y contratar hasta un número mínimo de asalariados permanentes. En otras palabras, la categoría comprende a los pequeños productores más capitalizados, a los que viven de su establecimiento pero no generan excedentes para crecer, y a los de menores recursos productivos, que no pueden vivir exclusivamente de lo generado en el establecimiento (Lattuada, 2014).

Esta sección no pretende atender a los programas de desarrollo rural implementados por el Estado Nacional y provincial en el contexto neoliberal (Pro Huerta, Cambio Rural, Programa Social Agropecuario, entre otros), sino que se interesa por observar las prácticas de acción colectiva y persistencia implementadas por los productores en la consecución de mejoras en la producción y, particularmente en la comercialización. La Cooperativa de Minifundistas y Tabacaleros Río Paraná en Misiones es una de las entidades que agrupa a los pequeños agricultores familiares. Se crea en 1987 y en 1994 modifica su estatuto otorgándole un carácter económico, pero también reivindicativo a la institución 
La cooperativa tendrá por objeto a) adquirir o producir por cuenta de la cooperativa para ser distribuidos entre los asociados, artículos de consumo, de uso personal, y del hogar; b) realizar toda operación en beneficios de los asociados dentro del espíritu de la cooperativa y de este estatuto; c) fomentar el espíritu de solidaridad y ayuda mutua entre los asociados y cumplir con el fin de crear una conciencia cooperativa; d) propender al mejoramiento económico de sus asociados y en especial a los más pobres y marginados de ellos. ${ }^{\text {xiv }}$

Esta cooperativa ubicada en Oberá (zona centro de la provincia) tiene una fuerte influencia y presencia del Movimiento Agrario de Misiones (MAM), formado -como se ha descripto- en la misma localidad en la década de 1970. La experiencia de los dirigentes es un elemento central para las decisiones que toma la entidad. La propuesta que sostienen es agrupar al sector agrario de Misiones, sin polarizarlos por tipo de producción. En este sentido, la entidad está integrada por productores de yerba mate, té, tabaco pero también por agricultores familiares que no se dedican a los principales cultivos de renta de la región. La institución es reconocida por dos aspectos principales: comercialización de yerba mate y por la presencia en los mercados solidarios, denominados ferias francas, de las cuales son gestores. Con respecto a la yerba mate, la marca Titrayju (Tierra, Trabajo y Justicia) presenta connotaciones sociales que la diferencian de sus pares cooperativos y de los molinos.

Nuestra yerba es el resultado de un trabajo familiar y artesanal. Los productores de la cooperativas son en su mayoría minifundistas, osea no superan las dos hectáreas. Así la yerba encierra más que una cuestión comercial, porque también cuidamos el medio ambiente, además es una reivindicación de estos colonos pobres, muchos de los cuales pertenecieron y pertenecen al MAM. Sufrieron las consecuencia de la dictadura por sus luchas y fueron los mas afectados por las políticas de los 90 . El nombre de la nuestra yerba se nos ocurrió a los productores, buscábamos algo que nos identifique de los demás pero que a la vez sea algo muy nuestro. Decidimos por tierra, trabajo y justicia por ser las cosas por la que más luchamos (Entrevista a Miguel Gonzales, ex presidente de la Cooperativa, Oberá, Misiones, julio de 2015).

La cooperativa tiene propuestas de desarrollo rural y territorial que no se limitan a la yerba mate o demás cultivos industriales; las mismas se materializan -como se enuncióen las denominadas ferias franca, en tanto mercados locales donde los agricultores comercializan directamente artículos antes destinados al auto- consumo (hortícolas, frutales, lácteos y carnes, panificados, dulces, encurtidos). Los rasgos centrales de estos mercados son la venta directa y la eximición de impuestos. Constituyen espacios de discusión en los cuales se abordan temas referidos a la agricultura familiar, la soberanía alimentaria, la biodiversidad, el trabajo asociativo, el cuidado de los recursos naturales, la valoración del rol de la mujer agricultora, la dignificación del trabajo a través del precio justo y la visualización de los agricultores familiares como productores de alimentos (Schvorer, 2003). 
La puesta en acción de estos mercados solidarios denota la proyección de la entidad en la comunidad donde se desarrolla, mientras en las memorias y balances se registran sus vínculos con el Estado y demás miembros de la sociedad civil. Sus objetivos consisten en lograr el mejoramiento de los ingresos y la calidad de vida de los productores, bregar para obtener productos naturales de buena calidad ofrecidos a los consumidores, fortalecer los mecanismos de auto-ayuda y solidaridad entre los productores, establecer relaciones solidarias con los consumidores y gestionar créditos.

Estas acciones no pueden entenderse desvinculadas del proceso socio-histórico que afecta de manera directa a la estructura agraria y a los sujetos sociales que las conforman, particularmente a la transformación de sus condiciones de producción y reproducción impuestas a partir de la década de 1970. Las crisis económicas que atraviesa el sector, expresadas en la caída de los precios de los cultivos de renta, principalmente a raíz de las formas de estructuración de la cadena de valor, así como también la supresión de los mecanismos institucionales de regulación y la creciente concentración del sector en la década de los 90, se materializan -como se enunció- en un proceso de creciente exclusión y deterioro de las condiciones de reproducción social (Alcoba y Dumarauf, 2011).

Este es el escenario en el cual se constituyen las estrategias de comercialización por parte de los agricultores familiares -muchos de ellos yerbateros- como una respuesta novedosa de los actores sociales, particularmente de los pequeños productores y colonos de la provincia, quienes deben poner en juego su capacidad de apropiación de recursos materiales y simbólicos para transformar sus propios mundos sociales y generar salidas para enfrentar la crisis. El proceso de construcción y consolidación de las ferias francas, por ejemplo, impacta en la forma de organizar el trabajo de la chacra, genera cambios en las condiciones de vida, en la construcción social de la subsistencia y la vida agraria de gran parte de los colonos misioneros.

Los mercados solidarios son ejemplos de cómo las estrategias e innovaciones que se manifiestan en relación a la inserción socio- productiva de los agricultores, expresan también en cambios en las relaciones sociales y comunitarias (Comelli y Guerreiro, 2007). Al mismo tiempo, permiten ser interpretadas como parte de un conjunto más amplio de experiencias que resisten a la hegemonía del capitalismo y al agronegocio y que revitalizan aquellas prácticas vinculadas a la economía campesina. Los productores en forma asociada y sin intermediarios intercambian directamente con los consumidores, al tiempo que definen los términos de dicho intercambio en función del interés colectivo y en base a vínculos de confianza. 


\section{Reflexiones finales}

El accionar del Estado para el agro de un área marginal y de frontera como lo es la región yerbatera argentina, se manifiesta con distintas lógicas y se presenta con diferentes aristas acorde al contexto. En tanto sistema económico social y cultural, la yerba mate (producción y comercialización) experimenta cambios estructurales para el periodo en estudio, siendo el sector más afectado los pequeños y medianos productores que integran la denominada agricultura familiar y forman parte -en su mayoría- de las asociaciones como cooperativas y federaciones.

El contexto en estudio inicia con la provincialización de Misiones en 1953. Las políticas destinadas a la yerba mate, principal cultivo agrario y de renta denota posturas disímiles y enfrentamientos entre distintas facciones. Sobresalen las críticas a las decisiones gubernamentales emanadas desde el "saber experto" y ejecutadas por la CRYM y más tarde por el INTA y el INYM. La organización y acción colectiva encarnada en las cooperativas y particularmente en el movimiento agrario ilustran la compleja trama del escenario yerbatero en las primeras décadas de la joven provincia.

Al compás de las modificaciones en el agro nacional -promovidas por el Estado Nación desde la década de 1980- Misiones se lanza a la adopción de nuevos cultivos (principalmente tabaco y forestoindustria) e intenta (a través de la proclamada modernidad) ajustarse a los requerimientos de un agro siempre dinámico. Sin embargo, la yerba mate continua como el principal cultivo, puesto que su producción y comercialización no se ajusta únicamente a cuestiones económicas sino que engloba pautas culturales del colono misionero.

A diferencia de otros cultivos industriales, la yerba mate no experimenta un cambio exponencial respecto de las innovaciones. Los cambios tecnológicos apuntan a mejorar los cultivos con la premisa de aumentar la productividad (densidad) por hectáreas que, en muchos casos siguen atados a rendimientos de mediados del siglo XX. El Estado nacional y provincial incursiona en este sentido y, a través de instituciones claves como el INTA o el Ministerio del Agro y la Producción buscan dinamizar el sector, acoplándose en estas premisas el INYM.

Los agricultores familiares generan estrategias de comercialización que les permite enfrentar -pero no superar- el cambio en el modelo de acumulación donde las desigualdades y las asimetrías permean la realidad y ubican a los grandes plantadores y molinos como los únicos ganadores. Ante la crisis de las cooperativas y asociaciones 
tradicionales, los productores promueven nuevos canales de comercialización como las ferias francas y mercados solidarios. El Estado se hace presente a través de créditos y asesoramiento técnico por intermedio de profesionales del INTA y el Ministerio del Agro.

En términos de valoración del producto corresponde destacar que en 2013 la yerba mate es declarada por el Congreso de la Nación como "Infusión Nacional" por intermedio de la Ley 26871. El rótulo de esta declaración es simbólico, pero en el escenario regional trasciende este aspecto e implica otras posibilidades para el sector agroindustrial yerbatero y para la promoción del desarrollo rural. A modo de ejemplo se enuncian nuevas formas de producción y comercialización; como así también "los usos" turísticos del producto a partir de la denominada "Ruta de la Yerba Mate" y las estrategias de agro turismo implementadas en las unidades domésticas de los productores vinculados al cultivo. Sin embargo, el sector yerbatero de la actual provincia de Misiones demanda más intervención en una actividad que denota cada vez mayor concentración, siendo la producción y la comercialización los eslabones que requieren de manera urgente la atención estatal.

\section{Bibliografía}

ALCOBA, Damían y DUMARAUF, Sergio. Agricultura Familiar. Del productor al consumidor, apuntes para el análisis de las ferias y mercados de la agricultura familiar en Argentina. Buenos Aires: Ediciones INTA, 2011.

ARZENO Mariana y PONCE, Mariana. "El rol del Estado y las políticas públicas de "desarrollo" en Misiones. Contradicciones emergentes con relación a la agricultura familiar". En MANZANAL, Mabel y PONCE, Mariana (organizadoras): La desigualdad ¿del desarrollo? Controversias y disyuntivas del desarrollo rural en el norte argentino. Buenos Aires: Editorial Ciccus. 2012.

BARTOLOME, Leopoldo. "Base social e ideología en las movilizaciones agraristas en Misiones entre 1971 y 1975". En: Desarrollo Económico, Revista de Ciencias Sociales. N 85 Vol. 22. Abril- Junio. Buenos Aires: IDES 1982.

BARTOLOME, Leopoldo: "Colonos, plantadores y agroindustrias. La explotación agrícola familiar en el sudeste de Misiones”. En: Desarrollo Económico, revista de ciencias sociales. $\mathrm{N}^{\circ} 58$ Volumen 15, julio-septiembre. Buenos Aires: IDES, 1975.

BOLSI, Alfredo: Misiones. Una aproximación geográfica al problema de la yerba mate y sus efectos en la ocupación del espacio y el poblamiento. En: Folia Histórica del Nordeste $\mathrm{N}^{\circ} 7$. Resistencia, Chaco 1986.

COMELLI, María y GUERREIRO, Luciana. Nuevas estrategias económicas y construcción de subjetividades políticas. Reflexiones desde una perspectiva de género a partir del caso de las ferias francas de Misiones, Argentina. Canadá: XXVII Latin American Studies Association Congress Montreal, 2007.

CONINAGRO- FEDECOOP. Yerba Mate en Misiones. Basado en modelos productivos de productores agropecuarios cooperativista. Buenos Aires: CONINAGRO, 2014.

EVANS, Peter. "El Estado como problema y como solución”. En Desarrollo Económico. Revista de Ciencias Sociales. N 140 V. 35. Buenos Aires: IDES, 1996. 
GORTARI, Javier. "Economía regional yerbatera: acumulación de capital con exclusión social". En: GORTARI, Javier; ROSENFELD, Víctor y OVIEDO, Alejandro: Dinámica agraria y políticas públicas. Desigualdades sociales y regionales. Posadas: Editorial Universitaria UNaM, 2016.

Instituto Interamericano de Cooperación para la Agricultura (IICA). Las Cooperativas Agropecuarias en la República Argentina: Diagnóstico y propuestas. Buenos Aires: Ministerio de Agricultura, Ganadería y Pesca, 2011.

LATTUADA, Mario. "Las asociaciones económicas no cooperativas de la agricultura familiar. Notas para su conceptualización y estudio". En: IICA Desarrollo de los agronegocios en en América Latina y el Caribe. San José de Costa Rica, 2014.

LATTUADA, Mario. Acción colectiva y corporaciones agrarias en la Argentina. Transformaciones institucionales a fines del siglo XX. Bernal: Editorial de la Universidad Nacional de Quilmes, 2006.

LATTUADA Mario; MARQUEZ, Susana; y NEME, Jorge. Desarrollo rural y política. Reflexiones sobre la experiencia argentina desde una perspectiva de gestión. Buenos Aires: Fundación Ciccus, 2012.

LOPEZ CASTRO, Natalia y PRIVIDERA, Guido. Repensar la agricultura familiar. Aportes para desentrañar la complejidad agraria pampeana. Buenos Aires: Ediciones CICCUS, 2011.

OZSLAK, Oscar; O’DONELL, Guillermo. "Estados y políticas estatales en América Latina: hacia una estrategia de investigación". En: REDES V. $2 \mathrm{~N}^{\circ}$ 4. Bernal: Universidad Nacional de Quilmes, 1995.

RAU, Víctor. Cosechando yerba mate. Estructuras sociales de un mercado laboral agrario en el nordeste argentino. Buenos Aires: Ediciones CICCUS, 2012.

REPETTO, Fabían. "Capacidad estatal: requisito para el mejoramiento de la política social en América Latina”. En: Documentos de Trabajo del INDES. BID, 2004.

SCHIAVONI, Gabriela y de MICCO, Carla. "Los ingenieros y los técnicos. Producción y circulación de conocimientos agrícolas en Misiones". En: BARTOLOME, Leopoldo y SCHIAVONI, Gabriela (Compiladores): Desarrollo y estudios rurales en Misiones. Posadas: Editorial Universitaria UNaM, 2008.

SCHIAVONI, Gabriela. Colonos y Ocupantes. Parentesco, reciprocidad y diferenciación social en la frontera agraria de Misiones. Posadas: Editorial Universitaria, 1995.

SCHVORER, Esther Lucia. "Etnografía de una feria franca. Estudio de un proyecto de desarrollo rural con productores familiares, Departamento Eldorado Misiones Argentina". Posadas: Tesis de Maestría en Antropología Social, Universidad Nacional de Misiones, 2003, Inédito.

SLUTZKY, Daniel. Estructura social agraria y agroindustrial del nordeste de la Argentina: desde la incorporación a la economía nacional al actual subdesarrollo concentrador y excluyente. Buenos Aires: Instituto Argentino de Desarrollo Económico (IADE), 2011.

${ }^{*}$ CONICET/ FHyCS UNaM (Argentina) lisandrodriguez@gmail.com

i INSTITUTO NACIONAL DE LA YERBA MATE (INYM). Plan Estratégico para el Sector Yerbatero (2013- 2020). Posadas, Misiones, 2013 
ii Entre 1881 y 1953 la actual provincia fronteriza de Misiones permanece bajo la tutela del Poder Ejecutivo Nacional como Territorio Nacional, en virtud de lo instituido por las Leyes 1.149 del 22/12/81 y la 1.532 del 16/10/84 Orgánica de Territorios Nacionales. La Ley 1.149, sancionada por el Congreso Nacional el 20 de diciembre de 18815 , establecía los límites de la provincia de Corrientes y con las tierras que quedaban fuera de los mismos, se organizaría una Gobernación General y se reglamentarían sus atribuciones.

iii Implica la libre plantación de yerba mate por parte de los productores, sin cupos establecido por la CRYM. Cuando estas plantaciones entran en producción provocan un desajuste en la balanza comercial.

iv COMISIÓN REGULADORA DE LA YERBA MATE (CRYM): Memorias y balances general años 1972- 1975. Secretaría de estado de agricultura y Ganadería. República Argentina, 1976

v Comisión Intergremial en Defensa de la Economía Yerbatera, Posadas, 1965

vi El cupo de importación fijado por la CRYM en 1966 es de $5000 \mathrm{~kg}$ de yerba mate proveniente del Paraguay. En el periodo comprendido entre 1960 y 1970 los saldos exportables apenas superan los $4500 \mathrm{~kg}$ en 1968, para luego volver a caer (CRYM, Memorias y Balances, 1971).

vii Cooperativa Yerbatera Aguará Guazú, Misiones, 1966

viii FEDERACIÓN DE COOPERATIVAS AGRÍCOLAS DE MISIONES (FEDECOOP), Memoria, Posadas, 1972

ix Amanecer Agrario, Órgano de difusión del MAM, Oberá, Misiones, 1972, Año 1 N. ${ }^{\circ} 4$

x Amanecer Agrario, Órgano de difusión del MAM, Oberá, Misiones, 1972, Año 1 N. ${ }^{\circ}$ 4. El resaltado es nuestro

xi Ministerio del Agro y la Producción de la Provincia de Misiones (MAGyP) Posadas, Misiones, s/f

xii INSTITUTO NACIONAL DE LA YERBA MATE (INYM). Plan Estratégico para el Sector Yerbatero (2013- 2020). Posadas, Misiones, 2013. El resaltado es nuestro

xiii Ministerio de Economía y Finanzas Públicas. Complejo Yerbatero. Argentina. 2011.

xiv Cooperativa de productores minifundistas Río Paraná. Oberá, Misiones, 1994 